\title{
Cognitive Remediation in Schizophrenia
}

\author{
Yoshio Kaneko ${ }^{1,2,3}$, Matcheri Keshavan ${ }^{1,3}$ \\ Department of Psychiatry, 'Beth Israel Deaconess Medical Center, ${ }^{2}$ Brigham and Women's Hospital, ${ }^{3}$ Harvard Medical School, Boston, \\ MA, USA
}

\begin{abstract}
Cognitive deficits in schizophrenia are pervasive, severe, and largely independent of the positive and negative symptoms of the illness. These deficits are increasingly considered to be core features of schizophrenia with evidence that the extent of cognitive impairment is the most salient predictor of daily functioning. Unfortunately, current schizophrenia treatment has been limited in addressing the cognitive deficits of the illness. Alterations in neuroplasticity are hypothesized to underpin these cognitive deficits, though preserved neuroplasticity may offer an avenue towards cognitive remediation. Key neuroplastic principles to consider in designing remediation interventions include ensuring sufficient intensity and duration of remediation programs, "bottom-up" training that proceeds from simple to complex cognitive processes, and individual tailoring of remediation regimens. We discuss several cognitive remediation programs, including cognitive enhancement therapy, which embrace these principles to target neurocognitive and social cognitive improvements and which havebeen demonstrated to be effective in schizophrenia. Future directions in cognitive remediation research include potential synergy with pharmacologic treatment, non-invasive stimulation techniques, and psychosocial interventions, identification of patient characteristics that predict outcome with cognitive remediation, and increasing the access to these interventions in front-line settings.
\end{abstract}

KEY WORDS: Schizophrenia; Cognition disorders/pathology; Cognition disorders/therapy; Cognition disorders/rehabilitation; Neuronal plasticity.

\section{COGNITIVE DEFICITS ARE A CORE ASPECT OF SCHIZOPHRENIA}

Cognitive deficits in schizophrenia have been identified as early as Kraeplin's original description of "dementia praecox," meaning cognitive decline with onset in youth. They are widely suggested to be a core feature of schizophrenia with increasing support for including impairments in cognition in the diagnostic criteria of the illness. ${ }^{1,2)}$ Extensive research has documented global cognitive impairment in schizophrenia, encompassing decrements in verbal and non-verbal memory, attention, executive function, processing speed, spatial ability, and abstraction. ${ }^{3)}$ Moreover, the extent of these deficits is substantial, such that patients with schizophrenia tend to test at one to two standard deviations below the mean for healthy controls. ${ }^{4,5)}$ Cognitive deficits are highly preva-

\footnotetext{
Received: April 9, 2012 / Revised: June 1, 2012

Accepted: June 2, 2012

Address for correspondence: Matcheri Keshavan, MD

Department of Psychiatry, Beth Israel Deaconess Medical Center,

330 Brookline Avenue, Boston, MA 02215, USA

Tel: +1-617-754-1256, Fax: +1-617-754-1250

E-mail: mkeshava@bidmc.harvard.edu
}

lent in schizophrenia, with estimates that as many as $98 \%$ of schizophrenia patients demonstrate impairment relative to their predicted cognitive function based on premorbid estimates of intelligence and parental education levels. ${ }^{6}$ These impairments are identifiable early in the illness, prior to treatment with antipsychotic medication, and persist throughout the course of the illness, further arguing for inclusion as core elements of schizophrenia. ${ }^{6,7)}$ While there is often speculation that measurement of cognitive functioning in schizophrenia is distorted by the presence of positive symptoms, no correlation between these measures was found in either the Clinical Antipsychotic Trials of Intervention Effectiveness (CATIE) trial or previous research examining these symptom groups. ${ }^{8-11)}$ Studies that examined cognitive functioning during both a psychotic episode and after the psychosis was in remission in the same group of patients found that cognitive performance was similar at both time points. ${ }^{12)}$ While negative symptoms and cognitive impairment are slightly correlated, the fact that only $15 \%$ of the variance is attributable to the negative symptoms suggests that deficits in cognition exist as an independent feature of schizophrenia. ${ }^{13)}$ Because unaffected first-degree relatives of

(c) This is an Open-Access article distributed under the terms of the Creative Commons Attribution Non-Commercial License (http://creativecommons.org/licenses/by-nc/3.0) which permits unrestricted non-commercial use, distribution, and reproduction in any medium, provided the original work is properly cited. 
schizophrenia patients demonstrate a pattern of cognitive deficits that is similar to that of the patients themselves, it is unlikely that the patients' cognitive impairments are simply secondary to schizophrenia symptoms or treatment. ${ }^{14,15)}$

Finally, the nature of cognitive deficits in schizophrenia is distinct from the impairments observed in other neuropsychiatric and neurodevelopmental disorders. The cognitive domains most impacted in schizophrenia include memory, attention, reasoning, problem solving, and social cognition. ${ }^{16)}$ Although patients with affective psychoses may present with a similar pattern of deficits, the magnitude of the deficits in schizophrenia is substantially greater. ${ }^{17)}$ A meta-analysis comparing cognitive deficits in patients with schizophrenia and bipolar disorder who had similar clinical and demographic characteristics demonstrated the impairments in schizophrenia to be, on average, 0.5 standard deviations greater than those in bipolar disorder. ${ }^{18)}$ Importantly, cognitive performance in schizophrenia appears to be stable across fluctuations in illness symptoms, while deficits in affective disorders are more closely tied to clinical state. ${ }^{10,17)}$ In a study of patients with psychosis, only those who had bipolar disorder had improvements in cognitive function with the resolution of the psychosis while those with schizophrenia performed at the same level cognitively regardless of changes in psychotic symptoms. ${ }^{19)}$ Moreover, patients who go on to develop schizophrenia exhibit cognitive decline over the course of childhood and adolescence which occurs prior to the onset of psychotic symptoms. ${ }^{20)}$ Conversely, those patients who go on to develop affective disorders do not demonstrate cognitive deficits until their affective symptoms have presented. ${ }^{21)}$ Although social cognition is impaired in both schizophrenia and autism, the two disorders can be distinguished by relative preservation of basic social perceptual mechanisms in schizophrenia, wherein abnormalities are tied to deficits in higher order social cognitive processes. ${ }^{22)}$ While cognitive deficits are widespread in neuropsychiatric disorders, the pattern and magnitude of these deficits in schizophrenia enables this disorder to be distinguished.

Cognitive deficits in schizophrenia are significantly correlated with functional outcome with regards to employment, independent living, community functioning, and social functioning. ${ }^{23-27)}$ Indeed, the link between cognitive performance and functional outcome is substantially stronger than that between psychosis and functional outcome. ${ }^{13)}$ While first generation antipsychotics can address the positive symptoms of schizophrenia, they appear to have modest, if any, effect on cognitive performance. ${ }^{28,29)}$ There was initial hope based on preclinical data that second generation antipsychotics would be more effective in improving cognitive performance. Subsequent clinical studies, however, have not demonstrated any meaningful difference in their effect on cognition between the first and second generation antipsychotics. $^{30,31)}$

\section{COGNITIVE DEFICITS AND NEUROPLASTICITY}

The above observations underscore the identification of cognitive deficits as a core feature of schizophrenia and a key path toward understanding the etiopathology of this illness. In recent years, there has been increasing evidence that the core cognitive deficits in schizophrenia may stem from neurodevelopmentally-mediated alterations in brain plasticity.

Neural plasticity refers to the ability of neural circuits to alter their structure, function, and connectivity in response to experience. Over 50 years ago, $\mathrm{Hebb}^{32)}$ postulated that synaptic plasticity is predicated on changes in synaptic efficacy, whereby repeated and persistent stimulation of the postsynaptic cell by the presynaptic cell increases the functional strength of the synapse connecting them. Experimental demonstration of this process, termed long-term potentiation (LTP), is accepted as a physiologic process underpinning learning and memory. ${ }^{33)}$ Since the identification of LTP, numerous other mechanisms of plasticity have been identified, with complex interactions between the different forms of plasticity and the networks in which they operate. There is increasing evidence that this plasticity is central to understanding both normal and disordered neural functioning. ${ }^{34)}$ While the exact mechanism of cognitive impairment in schizophrenia remains to be elucidated, disconnectivity within neural networks is gaining prominence as a theoretical model for functional impairment. ${ }^{35)}$ It is thought that abnormal neuroplasticity underlies this disconnectivity and therefore plays a central role in the cognitive deficits of schizophrenia. Evidence for this altered plasticity is converging along multiple lines, including studies in neurophysiology, neuropharmacology, neuropathology, and genetics. ${ }^{36}$ For example, a study of neural plasticity using transcranial magnetic stimulation (TMS) demonstrated abnormal plasticity in both medicated and unmedicated patients with schizophrenia relative to healthy controls. ${ }^{37)}$ Similarly, plasticity measured by electrophysiological responses to auditory conditioning is reduced in schizophrenia. ${ }^{38)}$ Pharmaco- 
logic agents, such as N-methyl D-aspartic acid (NMDA) antagonists, that can reproduce both the psychotic symptoms and cognitive deficits observed in schizophrenia have also been shown to affect neural plasticity. ${ }^{39)}$ Genetic studies consistently implicate altered synaptic plasticity in the pathogenesis of schizophrenia, as many of the strongest candidate genes for schizophrenia influence the development and regulation of neural networks. ${ }^{40,41)}$ Thus, it is increasingly believed that changes in neural plasticity may underlie the cognitive deficits and other clinical features of schizophrenia.

\section{NEUROPLASTICITY AS A THERAPEUTIC TARGET IN SCHIZOPHRENIA}

The significant personal and societal costs of schizophrenia highlight the importance of evidence-based interventions to reduce long-term morbidity. Unfortunately, to date, few successful efforts have been directed toward the treatment of cognitive deficits in schizophrenia, and clearly, alternate therapeutic targets are critically needed. In this context, the potential for employing the surviving functional neuroplasticity for therapeutic gain in schizophrenia and other neuropsychiatric disorders is of increasing importance.

Neuroplasticity is known to underlie functional recovery in a broad array of clinical conditions, including stroke, trauma, and spinal cord injuries. In a review of plasticity and training in animal models of the post-ischemic milieu, for example, Komitova et al. ${ }^{42)}$ documented changes in cortical thickness, brain weight, gene expression, dendritic branching, and cortical mapping that were associated with an enriched environment. Exposure to enriched environments is analogous to learning through training with similar mechanisms at play in modifying brain function. ${ }^{43)}$ Spontaneous clinical improvement in stroke, trauma, and spinal cord injuries is associated with observable changes at both the cellular level and within the functional connectivity of the relevant neural networks. ${ }^{44)}$ Moreover, therapies designed to employ the brain's plasticity have been shown to mimic or exceed these changes. For example, studies of post-stroke therapies demonstrate both restoration of functional organization and creation of neuronal projections ${ }^{45-47)}$ while similar studies of brain or spinal cord injuries correlate clinical improvement with observable changes in functional and structural neuroimaging. ${ }^{48,49)}$ There has been increasing interest in the possibility of involving neuroplasticity in the treatment of psychiatric disorders. Just as physical rehabilitation in the setting of trauma to the nervous system leads to functional improvement of the motor system, cognitive training is being developed across a variety of clinical conditions, from neurodevelopmental disorders $^{50)}$ to aging ${ }^{51)}$ to neuropsychiatric illnesses, including schizophrenia. ${ }^{52,53)}$ Such work has lead to the hypothesis that cognitive deficits in schizophrenia could be mitigated by treatment designed to improve the brain's structural and functional integrity via neuroplasticity. Cognitive remediation approaches seek to address this goal; we discuss herein, using physical exercise as an analogy, the key principles underlying the application of neuroplasticity in developing these interventions.

\section{The More One Exercises, the Better}

Evidence for neuroplasticity and reshaping of neural networks that is both time-dependent and reliant upon repetitive training converges across a number of research modalities. Animal models demonstrate two distinct processes in the development of LTP. In the first phase, there is increased synaptic efficiency, such that an increased number of the signals that reach the presynaptic cell are passed on to the postsynaptic cell. ${ }^{54)}$ This is mediated initially by post-synaptic glutamatergic NMDA receptors that detect coincident activity and induce both pre-synaptic and postsynaptic changes to increase efficiency. ${ }^{33)}$ Alpha-amino-3-hydroxy-5-methyl-4-isoxazole-propionic acid (AMPA) receptors, via either increased insertion at the postsynaptic membrane or modification of their signaling properties, seem to be the mechanism by which this efficiency is induced. ${ }^{55,56)}$ Analogous to the molecular mechanisms at play in LTP, human skill learning across multiple domains demonstrates rapid, but unsustained, initial learning. ${ }^{57)}$ Non-specific mechanisms, such as temporary changes in cortical representations, top-down organization related to task performance, and the increases in synaptic efficiency and neuronal excitability discussed above mediate this initial phase of performance improvement. ${ }^{58,59)}$ Topographically, the rapid phase of learning is associated with activation and increased functional connectivity of regions involved in directed attention, such as the prefrontal cortex, anterior cingulate cortex, and posterior parietal cortex. ${ }^{60,61)}$ These changes are not task-specific, but rather reflect generic heightened attention and effort resulting in activation of a set of regions now known as the task-positive network. ${ }^{62)}$

In contrast to these mechanisms, the second phase of LTP and learning is predicated upon synaptogenesis and reorganization of cortical representations. ${ }^{63)}$ Late-phase 
LTP is associated with an increased number of functional synaptic sites between hippocampal neurons in the rat brain. ${ }^{64)}$ Moreover, studies of rat hippocampal slices demonstrate that it is repetitive induction of late-phase LTP, rather than transitory excitation, that results in the generation of new synaptic structures. ${ }^{65)}$ Given its slower time course and development with continued activity, synaptogenesis may contribute to the maintenance and stability of synaptic potentiation, thus underscoring the importance of sustained activity for achieving long-term functional changes. ${ }^{54)}$ Whereas early phase learning is associated with activation of general attentional areas comprising the task-positive network, sustained learning is associated with regional activation with higher task specificity. ${ }^{66,67)}$ That is, as a performance becomes more practiced, it is increasingly linked to activation of the specific neural systems that underpin it and decreasingly reliant on top-down attention. For example, the second phase of learned motor tasks results in increased activation of the motor areas of the brain, including the supplementary motor area, cingulate motor cortex, cerebellum, and basal ganglia, at the same time that decreased activation of the task-positive network is observed. ${ }^{68,69)}$ In higher-order cognitive tasks, this reorganization may be represented not by increases in activity within a given region, but rather by increased functional connectivity in a distributed neural network. $^{67,70)}$ In order for neuroplasticity-mediated learning to result in durable functional changes, therefore, it is vital that the training be of sufficient duration to engage the second phase of learning. For example, a meta-analysis of cognitive remediation in schizophrenia, found that increased hours of remediation were associated with a larger effect size in verbal learning and verbal memory. ${ }^{71)}$ Vinogradov et al. ${ }^{58)}$ suggest that the relatively low intensity and brief duration of the studies of cognitive remediation to date may explain the fact that such meta-analyses have yet to document persistent, significant benefits to cognitive remediation. Future studies, therefore, will need to document the extent of treatment required to produce lasting results in order that adequate interventions be tested.

\section{Simple Exercise Should Precede Complex Tasks}

The second analogy to physical training is that it is better to start "bottom-up" with simple exercises, and gradually progress to more complex tasks.

Cognitive remediation approaches are likely to be more effective if simple cognitive processes are mastered before higher-level processes are addressed. Cognitive load theory formalizes this relationship, identifying increased ease of knowledge acquisition for information that builds upon existing knowledge relative to entirely novel information. ${ }^{72)}$ The known information enables more efficient processing of information such that an increasing proportion of the cognitive load is devoted to learning and problem solving. ${ }^{73)}$ A corollary to this statement is that impaired processing of simple information will undermine higher-order manipulation of this operation. Indeed, in schizophrenia patients, deficits in basic perceptual skills have been identified and shown to compromise performance of more complex cognitive operations. ${ }^{74)}$ For example, impairments in a tone-matching task, in which subjects are asked to determine if two tones are identical or not, are linked to deficits in the ability to interpret another person's emotions based on auditory information. ${ }^{75}$ Similarly, deficits in the processing of syllables are related to decreases in verbal learning and general cognition in both schizophrenia patients and healthy controls. ${ }^{76)}$ Because deficits in simple perception necessitate an increased attentional load and recruitment of top-down operations to achieve basic processing, ${ }^{77)}$ fewer top-down resources are available for higher-level cognitive operations. $^{78)}$

Given this connection, there is increasing emphasis on the idea that training targeting basic sensory processes and simple cognitive functions will ultimately benefit higher-level cognitive operations. A study of aging adults demonstrated that training that produced improvement in early visual processing lead to improvements in working memory. ${ }^{79)}$ Similar studies are beginning to emerge in schizophrenia research. For example, Adcock et al. ${ }^{77)}$ have shown that an auditory training regimen can induce improvements in impaired sensory processing, such as the ability to distinguish two similar syllables. More importantly, they demonstrated that these basic improvements were associated with improvements in higher order functions, including linguistic processing, verbal cognition, and general cognition and that these changes were durable six months after training had concluded. ${ }^{77)}$ Similarly, a social cognition training regimen that included practice in the basic skill of emotion perception was demonstrated to improve not only social cognition, but also social functioning in patients with schizophrenia, suggesting that the benefits generalize from test performance to actual functioning. ${ }^{80)}$ Cognitive therapies, therefore, must both recognize and address the perceptual processing impairments that are present in schizophrenia if maximal improvements in higher order cognitive func- 
tions are to be achieved.

\section{Personalized Exercises Work Better}

Finally, and again by analogy to physical exercise, interventions are most effective if they are tailored individually to each person's capabilities and limitations

An important aspect of individual tailoring of one's exercise regime is to monitor performance and gradually increase the difficulty; if too hard, one makes errors, and if too easy, the task gets boring. For maximal benefit therefore, it is important to have the tasks slightly above the threshold of challenge. ${ }^{81)}$ Studies of learning and neuroplasticity conducted in the elderly demonstrate the importance of balancing attention, reward, and novelty in order to produce efficient learning. It is the balance of these features that lead to optimal engagement of the neuromodulatory systems, including the acetylcholine, dopamine, norepinephrine, and serotonin signaling systems, which in turn modulate plasticity. ${ }^{82)}$ The need to maintain this balance implies a need for training to increase in difficulty as increased learning occurs such that training remains at threshold. The importance of this principle is highlighted by a study of working memory training in patients with attention deficit hyperactivity disorder (ADHD) in which a training program with graded difficulty progression resulted in cognitive improvement while the same exercise organized in a non-progressive way did not lead to increased performance. ${ }^{83)}$

One of the learning approaches that has been observed to enhance learning is "errorless learning," that is, intensive training at threshold. In contrast to conventional trial and error learning, which requires the learner to remember and incorporate feedback, errorless learning is based on repetitive exposure designed for the learner to succeed in a majority of trials, with difficulty gradually increasing as the learner develops mastery. Errorless learning takes advantage of implicit (learning without conscious awareness) learning processes that may be intact in schizophrenia; ${ }^{84,85)}$ treatment induced improvements in implicit learning systems may thus help to restore impaired working memory and explicit memory processes. ${ }^{58)}$ Errorless learning has been demonstrated to be effective in schizophrenia patients in both formal memory assessments and a study of work performance carried out in a community mental health center setting. ${ }^{86,87)}$ Learning is also enhanced by personally salient stimuli. There is overwhelming evidence that emotionally-charged events enhance selective memory consolidation, perhaps mediated by the amygdale; ${ }^{88)}$ emotionally-charged events are remembered better than emotionally neutral experiences, and emotion may enhance the subjective sense of recollection more than memory accuracy. ${ }^{89)}$ Cognitive therapies that manage to personally engage the learner are thus more likely to produce meaningful and lasting improvement.

\section{COGNITIVE REMEDIATION APPROACHES}

Cognitive remediation is an intervention that seeks to enhance the neurocognitive skills in patients relevant to their recovery goals. Two distinct and complementary cognitive remediation approaches have been developed: the compensatory and the restorative approaches. Compensatory approaches utilize environmental supports and adaptive strategies to bypass cognitive deficits and improve target behaviors and functional outcomes in individuals with schizophrenia. ${ }^{90)}$ In this paper, we focus on cognitive restoration approaches that seek to improve deficits in one or another cognitive function.

Wagner ${ }^{91)}$ and Spaulding et al. ${ }^{92)}$ were among the first investigators to show that cognitive deficits in schizophrenia respond to remedial training. Several remediation approaches have since been developed, ranging from computer-based to paper and pencil and drill-and-practice to therapist-guided strategy coaching. These therapies rely on a range of basic cognitive processes, including perception, working memory, attention, and social cognition, along with combinations of these functions. In a metaanalysis of 26 studies, McGurk et al ${ }^{71)}$ found mean effect sizes of 0.41 for cognitive improvement and 0.36 for functional outcome. While effect sizes did not differ with regard to the type of remediation, a larger effect size in verbal memory was associated with more hours of remediation (0.57) compared with fewer hours (0.29). ${ }^{71)}$ A more recent meta-analysis of 40 cognitive remediation studies conducted between 1973 and 2009 demonstrated a mean global cognition effect size of $0.45{ }^{53)}$ Clearly, the effect sizes, though significant, were modest. Functional outcomes were significantly better in studies where cognitive remediation was combined with some other form of rehabilitation and when it included strategy coaching. Interventions are likely to be more successful when the skills trained closely approximate those needed in daily life. There is also evidence that patient variables such as levels of intrinsic and extrinsic motivation interact with treatment variables to produce a beneficial response to cognitive remediation. Going forward, better, multi-component strategies to enhance the therapeutic efficacy of 
cognitive remediation need to be identified. In designing effective cognitive remediation approaches, it is also important to adhere to the neuroscientific principles discussed earlier, i.e., an effective combination of drill and practice, "bottom-up" and "top-down" approaches, and personalized adaptation of training. Cognitive training approaches that are intrinsically motivating, used in a meaningful game-like context, those that personalize learning materials into themes of high interest value, and those that maximize patient control over the learning process are likely to be the most effective. ${ }^{93)}$

Cognitive enhancement therapy (CET) is a multi-component cognitive remediation approach, pioneered by the late Professor Gerard E. Hogarty in our group in Pittsburgh, that incorporates all of the above principles (cognitiveenhancementtherapy.com) ${ }^{94)} \mathrm{CET}$ is designed to provide enriched cognitive experiences through targeted and integrated neurocognitive and social-cognitive training. The focus is on enhancing both "bottom-up" processing of critical social stimuli, with "top-down" executive control over distracting information and emotional arousal. Through the integration of computer-based cognitive exercises in attention, training, and problem-solving, with an active social-cognitive group experience designed to facilitate perspective-taking, gistful processing of information, and social context appraisal, CET is thought to provide the requisite experiences needed to enhance neural processing and achieve adult cognitive milestones. The intervention involves weekly sessions for up to two years.

Evidence to date indicates that CET can successfully improve social and non-social cognitive impairments in schizophrenia. In a randomized-controlled study of 121 patients with chronic schizophrenia, Hogarty et al ${ }^{95)}$ demonstrated significant improvements in cognitive measures such as neurocognition, processing speed, and cognitive style in patients receiving CET relative to those undergoing enriched supportive therapy. This differential was evident in the first year of training and continued to increase throughout the two-year training period. Similarly, a study of CET in patients with early-course schizophrenia or schizoaffective disorder identified ongoing improvement in cognitive measures from year one to year two of treatment. ${ }^{94)}$ While CET demonstrated only moderate beneficial effect size $(\mathrm{d}=0.46)$ in enhancing neurocognitive function, strong differential effects $(\mathrm{d}>1.00)$ favoring CET on social cognition, cognitive style, and social adjustment composites were observed. ${ }^{94)}$ These findings echoed a previous study demonstrating improve- ments in social cognition following CET in early course schizophrenia. ${ }^{23)}$ Improvement in the employment rates and of patients in the CET cohort suggests that the benefits extend beyond formal testing to daily functioning. ${ }^{94)}$ This functional improvement was mediated by neurocognitive gains, primarily in executive functioning, and social-cognitive gains in emotion management. ${ }^{52)}$ Importantly, follow-up studies of each of these groups showed persistence in the functional benefits of CET at one-year post-treatment, suggesting that the therapy had engaged the learning mechanisms necessary for sustained change. ${ }^{96,97)}$

The therapeutic effects of CET may capitalize on brain plasticity processes to offer neuroprotection and improved brain function in the fronto-temporal areas implicated in cognitive impairment. ${ }^{52)}$ Over the course of two years, schizophrenia patients receiving CET had greater preservation of gray matter volume in the left hippocampus, parahippocampal gyrus, and fusiform gyrus, and significantly greater gray matter increases in the left amygdala compared with those who received enriched supportive therapy. ${ }^{98)}$ Gray matter preservation in the left parahippocampal and fusiform gyrus and greater gray matter increases in the left amygdala were significantly related to improved cognition. ${ }^{98)}$ These structural changes are likely mediated by neuroplasticity in the relevant signaling networks and may be the mechanism by which the beneficial cognitive effects of CET occur. Interestingly, pre-treatment whole brain cortical surface area and gray matter volume ("cortical reserve") significantly moderated the effects of CET on social cognition, though not on neurocognition. ${ }^{99)}$ Greater cortical reserve, particularly in the temporal cortex, predicted a rapid social-cognitive response to CET in the first year of treatment. Given the fact that patients with less neurobiological reserve achieved a comparable social-cognitive response by the second year, however, it is possible that the early response reflects the recruitment of "surplus" neural capacity, while later developing changes are due to the expansion or increased connectivity of the networks underlying these functions. ${ }^{99)}$

\section{FUTURE DIRECTIONS}

While cognitive remediation approaches are promising, many questions remain. Several future directions are on the horizon and are briefly outlined here.

\section{Synergy with Pharmacological Treatments}

It is important to examine how one can synergistically 
apply pharmacologic and psychosocial approaches. Pharmacological agents that may have a pro-cognitive benefit need to be developed and tested in combination with cognitive remediation. In recent years, psychopharmacological researchers have been increasingly drawn toward efforts to identify therapeutic agents that may address cognitive deficits in schizophrenia. The Measurement and Treatment Research to Improve Cognition in Schizophrenia (MATRICS) initiative has sought to develop cognitive batteries that are sensitive to detect treatment effects, and the Treatment Units for Research on Neurocognition in Schizophrenia (TURNS) network has been spearheading efforts to test potential pro-cognitive compounds for efficacy. ${ }^{13,100)}$ Several potential targets have been identified for enhancing cognition in schizophrenia, including dopaminergic, serotonergic, histaminergic, cholinergic, glutamatergic, $\gamma$-aminobutyric acid (GABA)ergic, adrenergic, and sigma receptors. ${ }^{101,102)}$ For example, observations that individuals with schizophrenia smoke at a higher rate than the general population have led to the theory that these individuals may be attempting to "self-medicate" cognitive deficits associated with illness and/or antipsychotic treatment. Selective $\alpha 7$ and $\alpha 4 \beta 2$ nicotinic receptor agonists, have shown promising, but inconsistent, results in studies to date. ${ }^{103,104)}$ Glutamatergic receptors, both ionotropic (NMDA, AMPA, and kainate-sensitive) and metabotropic $\left(\mathrm{mGluR}_{1-8}\right)$ types, have been targeted for improving cognition. ${ }^{102)}$ Because glycine modulates NMDA receptor function, the glycine agonist $\mathrm{D}$-serine is under investigation and has shown positive preliminary results, while, inhibitors of glycine reuptake are also being studied. ${ }^{105)}$ Studies of GABAergic agents, such as MK-0777-a GABA(A) $\alpha 2 / \alpha 3$ partial agonist have produced conflicting results thus far. ${ }^{106)}$ Modafinil and d-amphetamine have promising pro-cognitive effects, though their clinical use for this purpose in schizophrenia patients remains to be established. ${ }^{107,108)}$ It is an intriguing, though thus far untested, possibility that while pharmacological agents in and of themselves may have modest efficacy on cognitive deficits in schizophrenia, they may prove to have synergistic effects when used in combination with psychosocial approaches to cognitive remediation.

\section{Non-Invasive Stimulation Techniques}

Other, non-pharmacological, approaches to enhance neuroplasticity, such as transcranial magnetic stimulation (TMS) ${ }^{109)}$ and transcranial direct current stimulation (tDCS), ${ }^{110)}$ need to be considered as potential adjuncts to cognitive remediation. A recent study suggests that TMS applied to the prefrontal cortex may improve cognitive deficits in schizophrenia. ${ }^{111)}$ Similarly, anodal tDCS, applied to the dorsolateral prefrontal cortex has been shown to improve cognitive functions including learning and memory in both healthy adults and in schizophrenia patients. ${ }^{112,113)}$ Again, few studies have examined the potential synergistic effects of these approaches with cognitive remediation.

\section{Prediction and Personalization of Treatment}

Given how labor intensive such approaches are, it is essential to match patients with the specific cognitive remediation therapy to which they are most likely to respond. It is therefore critical to identify clinical, neurobiological, and genetic predictors of positive response to cognitive remediation interventions. For example, pretreatment learning potential, the ability to attain and utilize cognitive skills after cognitive training, is a measure that has been shown to predict response to cognitive remediation. ${ }^{114)}$ Other studies have highlighted motivation $^{115)}$ and the combination of sustained attention and working memory as the key predictors of response, with the latter two factors particularly associated with generalized functional improvement. ${ }^{116)}$ Genetic polymorphisms that may mediate some aspects of cognitive function in schizophrenia, such as catechol-o-methyl transferase, have been investigated as potential predictors of outcome with cognitive remediation, though with inconsistent results thus far. ${ }^{117,118)}$ As research proceeds, therefore, appropriate pairing of patients with the cognitive remediation technique most likely to benefit them will maximize the likelihood of successful functional improvement.

Cognitive remediation is a promising approach to improve real-world functioning in patients with schizophrenia. Future studies must further elucidate the neural mechanisms underlying cognitive remediation and determine the optimal means by which to harness neuroplasticity. With regards to implementation, it will be important to develop cognitive remediation that can be delivered in community settings and to train front-line clinicians to do so. There is increasing evidence that cognitive remediation is most effective when combined with other psychosocial treatments, such as social skills training and supportive employment. Further work is needed to develop comprehensive approaches to cognitive remediation that incorporate key therapeutic principles from a variety of treatment modalities. 


\section{REFERENCES}

1. Hyman SE, Fenton WS. Medicine. What are the right targets for psychopharmacology? Science 2003;299:350351.

2. Keefe RS, Fenton WS. How should DSM-V criteria for schizophrenia include cognitive impairment? Schizophr Bull 2007;33:912-920.

3. Heinrichs RW, Zakzanis KK. Neurocognitive deficit in schizophrenia: a quantitative review of the evidence. Neuropsychology 1998;12:426-445.

4. Saykin AJ, Shtasel DL, Gur RE, Kester DB, Mozley LH, Stafiniak P, et al. Neuropsychological deficits in neuroleptic naive patients with first-episode schizophrenia. Arch Gen Psychiatry 1994;51:124-131.

5. Wilk CM, Gold JM, Humber K, Dickerson F, Fenton WS, Buchanan RW. Brief cognitive assessment in schizophrenia: normative data for the Repeatable Battery for the Assessment of Neuropsychological Status. Schizophr Res 2004;70:175-186.

6. Keefe RS, Eesley CE, Poe MP. Defining a cognitive function decrement in schizophrenia. Biol Psychiatry 2005;57: 688-691.

7. Hoff AL, Svetina C, Shields G, Stewart J, DeLisi LE. Ten year longitudinal study of neuropsychological functioning subsequent to a first episode of schizophrenia. Schizophr Res 2005;78:27-34.

8. Keefe RS, Bilder RM, Harvey PD, Davis SM, Palmer BW, Gold JM, et al. Baseline neurocognitive deficits in the CATIE schizophrenia trial. Neuropsychopharmacology 2006;31:2033-2046.

9. Bilder RM, Goldman RS, Robinson D, Reiter G, Bell L, Bates JA, et al. Neuropsychology of first-episode schizophrenia: initial characterization and clinical correlates. Am J Psychiatry 2000;157:549-559.

10. Goldberg TE, Gold JM, Greenberg R, Griffin S, Schulz SC, Pickar D, et al. Contrasts between patients with affective disorders and patients with schizophrenia on a neuropsychological test battery. Am J Psychiatry 1993;150:13551362.

11. Mohamed S, Paulsen JS, O'Leary D, Arndt S, Andreasen N. Generalized cognitive deficits in schizophrenia: a study of first-episode patients. Arch Gen Psychiatry 1999;56:749754.

12. Finkelstein JR, Cannon TD, Gur RE, Gur RC, Moberg P. Attentional dysfunctions in neuroleptic-naive and neuroleptic-withdrawn schizophrenic patients and their siblings. J Abnorm Psychol 1997;106:203-212.

13. Green MF, Nuechterlein KH, Gold JM, Barch DM, Cohen $\mathrm{J}$, Essock S, et al. Approaching a consensus cognitive battery for clinical trials in schizophrenia: the NIMHMATRICS conference to select cognitive domains and test criteria. Biol Psychiatry 2004:56:301-307.

14. Cannon TD, Zorrilla LE, Shtasel D, Gur RE, Gur RC, Marco EJ, et al. Neuropsychological functioning in siblings discordant for schizophrenia and healthy volunteers. Arch Gen Psychiatry 1994;51:651-661.

15. Heydebrand G. Cognitive deficits in the families of patients with schizophrenia. Curr Opin Psychiatry 2006;19:277281.

16. Nuechterlein KH, Barch DM, Gold JM, Goldberg TE, Green MF, Heaton RK. Identification of separable cognitive factors in schizophrenia. Schizophr Res 2004;72:2939.

17. Buchanan RW, Davis M, Goff D, Green MF, Keefe RS,
Leon AC, et al. A summary of the FDA-NIMH-MATRICS workshop on clinical trial design for neurocognitive drugs for schizophrenia. Schizophr Bull 2005;31:5-19.

18. Krabbendam L, Arts B, van Os J, Aleman A. Cognitive functioning in patients with schizophrenia and bipolar disorder: a quantitative review. Schizophr Res 2005;80: 137-149.

19. Harvey PD, Docherty NM, Serper MR, Rasmussen M. Cognitive deficits and thought disorder: II. An 8-month followup study. Schizophr Bull 1990;16:147-156.

20. Keefe RS. Cognitive deficits in patients with schizophrenia: effects and treatment. J Clin Psychiatry 2007;68(Suppl 14): 8-13.

21. Cannon M, Caspi A, Moffitt TE, Harrington H, Taylor A, Murray RM, et al. Evidence for early-childhood, pandevelopmental impairment specific to schizophreniform disorder: results from a longitudinal birth cohort. Arch Gen Psychiatry 2002;59:449-456.

22. Sasson NJ, Pinkham AE, Carpenter KL, Belger A. The benefit of directly comparing autism and schizophrenia for revealing mechanisms of social cognitive impairment. $J$ Neurodev Disord 2011;3:87-100.

23. Eack SM, Hogarty GE, Greenwald DP, Hogarty SS, Keshavan MS. Cognitive enhancement therapy improves emotional intelligence in early course schizophrenia: preliminary effects. Schizophr Res 2007;89:308-311.

24. Fett AK, Viechtbauer W, Dominguez MD, Penn DL, van Os J, Krabbendam L. The relationship between neurocognition and social cognition with functional outcomes in schizophrenia: a meta-analysis. Neurosci Biobehav Rev 2011;35:573-588.

25. Green MF, Nuechterlein KH. Should schizophrenia be treated as a neurocognitive disorder? Schizophr Bull 1999;25:309-319.

26. Green MF, Kern RS, Braff DL, Mintz J. Neurocognitive deficits and functional outcome in schizophrenia: are we measuring the "right stuff"? Schizophr Bull 2000;26:119136.

27. Gold JM, Goldberg RW, McNary SW, Dixon LB, Lehman AF. Cognitive correlates of job tenure among patients with severe mental illness. Am J Psychiatry 2002;159:13951402.

28. Hill SK, Bishop JR, Palumbo D, Sweeney JA. Effect of second-generation antipsychotics on cognition: current issues and future challenges. Expert Rev Neurother 2010; 10:43-57.

29. Mishara AL, Goldberg TE. A meta-analysis and critical review of the effects of conventional neuroleptic treatment on cognition in schizophrenia: opening a closed book. Biol Psychiatry 2004;55:1013-1022.

30. Davidson $M$, Galderisi $S$, Weiser $M$, Werbeloff $N$, Fleischhacker WW, Keefe RS, et al. Cognitive effects of antipsychotic drugs in first-episode schizophrenia and schizophreniform disorder: a randomized, open-label clinical trial (EUFEST). Am J Psychiatry 2009;166:675-682.

31. Keefe RS, Bilder RM, Davis SM, Harvey PD, Palmer BW, Gold JM, et al; CATIE Investigators; Neurocognitive Working Group. Neurocognitive effects of antipsychotic medications in patients with chronic schizophrenia in the CATIE Trial. Arch Gen Psychiatry 2007;64:633-647.

32. Hebb DO. The organization of behavior: A neuropsychological theory. Wiley;1949.

33. Bliss TV, Collingridge GL. A synaptic model of memory: long-term potentiation in the hippocampus. Nature 1993; 361:31-39. 
34. Citri A, Malenka RC. Synaptic plasticity: multiple forms, functions, and mechanisms. Neuropsychopharmacology 2008; 33:18-41.

35. Friston KJ. The disconnection hypothesis. Schizophr Res 1998;30:115-125.

36. Stephan KE, Baldeweg T, Friston KJ. Synaptic plasticity and dysconnection in schizophrenia. Biol Psychiatry 2006; 59:929-939.

37. Daskalakis ZJ, Christensen BK, Fitzgerald PB, Chen R. Dysfunctional neural plasticity in patients with schizophrenia. Arch Gen Psychiatry 2008;65:378-385.

38. Mears RP, Spencer KM. Electrophysiological assessment of auditory stimulus-specific plasticity in schizophrenia. Biol Psychiatry 2012;71:503-511.

39. Domino EF, Mirzoyan D, Tsukada H. N-methyl-D-aspartate antagonists as drug models of schizophrenia: a surprising link to tobacco smoking. Prog Neuropsychopharmacol Biol Psychiatry 2004;28:801-811.

40. Harrison PJ, Weinberger DR. Schizophrenia genes, gene expression, and neuropathology: on the matter of their convergence. Mol Psychiatry 2005;10:40-68.

41. Balu DT, Coyle JT. Neuroplasticity signaling pathways linked to the pathophysiology of schizophrenia. Neurosci Biobehav Rev 2011;35:848-870.

42. Komitova M, Johansson BB, Eriksson PS. On neural plasticity, new neurons and the postischemic milieu: an integrated view on experimental rehabilitation. Exp Neurol 2006; 199:42-55.

43. Will B, Galani R, Kelche C, Rosenzweig MR. Recovery from brain injury in animals: relative efficacy of environmental enrichment, physical exercise or formal training (1990-2002). Prog Neurobiol 2004;72:167-182.

44. Cramer SC, Sur M, Dobkin BH, O'Brien C, Sanger TD, Trojanowski JQ, et al. Harnessing neuroplasticity for clinical applications. Brain 2011;134:1591-1609.

45. Buma FE, Lindeman E, Ramsey NF, Kwakkel G. Functional neuroimaging studies of early upper limb recovery after stroke: a systematic review of the literature. Neurorehabil Neural Repair 2010;24:589-608.

46. Carey JR, Kimberley TJ, Lewis SM, Auerbach EJ, Dorsey $\mathrm{L}$, Rundquist $\mathrm{P}$, et al. Analysis of $\mathrm{FMRI}$ and finger tracking training in subjects with chronic stroke. Brain 2002;125: 773-788.

47. Chen P, Goldberg DE, Kolb B, Lanser M, Benowitz LI. Inosine induces axonal rewiring and improves behavioral outcome after stroke. Proc Natl Acad Sci U S A 2002;99: 9031-9036.

48. Gauthier LV, Taub E, Perkins C, Ortmann M, Mark VW, Uswatte G. Remodeling the brain: plastic structural brain changes produced by different motor therapies after stroke. Stroke 2008;39:1520-1525.

49. Sawaki L, Butler AJ, Leng X, Wassenaar PA, Mohammad $\mathrm{YM}$, Blanton $\mathrm{S}$, et al. Constraint-induced movement therapy results in increased motor map area in subjects 3 to 9 months after stroke. Neurorehabil Neural Repair 2008;22:505-513.

50. Halperin JM, Healey DM. The influences of environmental enrichment, cognitive enhancement, and physical exercise on brain development: can we alter the developmental trajectory of ADHD? Neurosci Biobehav Rev 2011;35:621634.

51. Tardif S, Simard M. Cognitive stimulation programs in healthy elderly: a review. Int J Alzheimers Dis 2011;2011: 378934.

52. Eack SM, Pogue-Geile MF, Greenwald DP, Hogarty SS,
Keshavan MS. Mechanisms of functional improvement in a 2-year trial of cognitive enhancement therapy for early schizophrenia. Psychol Med 2011;41:1253-1261.

53. Wykes T, Huddy V, Cellard C, McGurk SR, Czobor P. A meta-analysis of cognitive remediation for schizophrenia: methodology and effect sizes. Am J Psychiatry 2011;168: 472-485.

54. Muller D, Nikonenko I, Jourdain P, Alberi S. LTP, memory and structural plasticity. Curr Mol Med 2002;2:605-611.

55. Malinow R, Malenka RC. AMPA receptor trafficking and synaptic plasticity. Annu Rev Neurosci 2002;25:103-126.

56. Barria A, Muller D, Derkach V, Griffith LC, Soderling TR. Regulatory phosphorylation of AMPA-type glutamate receptors by CaM-KII during long-term potentiation. Science 1997;276:2042-2045.

57. Dayan E, Cohen LG. Neuroplasticity subserving motor skill learning. Neuron 2011;72:443-454.

58. Vinogradov S, Fisher M, de Villers-Sidani E. Cognitive training for impaired neural systems in neuropsychiatric illness. Neuropsychopharmacology 2012;37:43-76.

59. Classen J, Liepert J, Wise SP, Hallett M, Cohen LG. Rapid plasticity of human cortical movement representation induced by practice. J Neurophysiol 1998;79:1117-1123.

60. Floyer-Lea A, Matthews PM. Distinguishable brain activation networks for short- and long-term motor skill learning. J Neurophysiol 2005;94:512-518.

61. Sakai K, Hikosaka O, Miyauchi S, Sasaki Y, Fujimaki N, Pütz B. Presupplementary motor area activation during sequence learning reflects visuo-motor association. J Neurosci 1999; 19:RC1.

62. Fox MD, Snyder AZ, Vincent JL, Corbetta M, Van Essen DC, Raichle ME. The human brain is intrinsically organized into dynamic, anticorrelated functional networks. Proc Natl Acad Sci U S A 2005;102:9673-9678.

63. Buchs PA, Muller D. Induction of long-term potentiation is associated with major ultrastructural changes of activated synapses. Proc Natl Acad Sci U S A 1996;93:80408045.

64. Bolshakov VY, Golan H, Kandel ER, Siegelbaum SA. Recruitment of new sites of synaptic transmission during the cAMP-dependent late phase of LTP at CA3-CA1 synapses in the hippocampus. Neuron 1997;19:635-651.

65. Tominaga-Yoshino K, Urakubo T, Okada M, Matsuda H, Ogura A. Repetitive induction of late-phase LTP produces long-lasting synaptic enhancement accompanied by synaptogenesis in cultured hippocampal slices. Hippocampus 2008;18:281-293.

66. Petersen SE, van Mier H, Fiez JA, Raichle ME. The effects of practice on the functional anatomy of task performance. Proc Natl Acad Sci U S A 1998;95:853-860.

67. Kelly AM, Garavan H. Human functional neuroimaging of brain changes associated with practice. Cereb Cortex 2005; 15:1089-1102.

68. Debaere F, Wenderoth N, Sunaert S, Van Hecke P, Swinnen SP. Changes in brain activation during the acquisition of a new bimanual coodination task. Neuropsychologia 2004;42:855-867.

69. Frutiger SA, Strother SC, Anderson JR, Sidtis JJ, Arnold $\mathrm{JB}$, Rottenberg DA. Multivariate predictive relationship between kinematic and functional activation patterns in a PET study of visuomotor learning. Neuroimage 2000;12: 515-527.

70. Büchel C, Coull JT, Friston KJ. The predictive value of changes in effective connectivity for human learning. Science 1999;283:1538-1541. 
71. McGurk SR, Twamley EW, Sitzer DI, McHugo GJ, Mueser KT. A meta-analysis of cognitive remediation in schizophrenia. Am J Psychiatry 2007;164:1791-1802.

72. Sweller J. Cognitive load during problem solving: Effects on learning. Cognitive Science 1988;12:257-285.

73. van Merriënboer J, Sweller J. Cognitive load theory and complex learning: Recent developments and future directions. Educ Psychol Rev 2005;17:147-177.

74. Kugler BT, Caudrey DJ. Phoneme discrimination in schizophrenia. Br J Psychiatry 1983;142:53-59.

75. Leitman DI, Foxe JJ, Butler PD, Saperstein A, Revheim N, Javitt DC. Sensory contributions to impaired prosodic processing in schizophrenia. Biol Psychiatry 2005;58:5661.

76. Dale CL, Findlay AM, Adcock RA, Vertinski M, Fisher M, Genevsky A, et al. Timing is everything: neural response dynamics during syllable processing and its relation to higher-order cognition in schizophrenia and healthy comparison subjects. Int J Psychophysiol 2010;75:183-193.

77. Adcock RA, Dale C, Fisher M, Aldebot S, Genevsky A, Simpson GV, et al. When top-down meets bottom-up: auditory training enhances verbal memory in schizophrenia. Schizophr Bull 2009;35:1132-1141.

78. Javitt DC, Liederman E, Cienfuegos A, Shelley AM. Panmodal processing imprecision as a basis for dysfunction of transient memory storage systems in schizophrenia. Schizophr Bull 1999;25:763-775.

79. Berry AS, Zanto TP, Clapp WC, Hardy JL, Delahunt PB, Mahncke HW, et al. The influence of perceptual training on working memory in older adults. PLoS One 2010; 5:e11537.

80. Roberts DL, Penn DL. Social cognition and interaction training (SCIT) for outpatients with schizophrenia: a preliminary study. Psychiatry Res 2009;166:141-147.

81. Csikszentmihalyi M. Flow: the psychology of optimal experience. 1st ed. New York: Harper and Row;1990.

82. Mahncke HW, Connor BB, Appelman J, Ahsanuddin ON, Hardy JL, Wood RA, et al. Memory enhancement in healthy older adults using a brain plasticity-based training program: a randomized, controlled study. Proc Natl Acad Sci U S A 2006;103:12523-12528.

83. Klingberg T, Fernell E, Olesen PJ, Johnson M, Gustafsson $\mathrm{P}$, Dahlström K, et al. Computerized training of working memory in children with ADHD--a randomized, controlled trial. J Am Acad Child Adolesc Psychiatry 2005;44:177186.

84. Danion JM, Meulemans T, Kauffmann-Muller F, Vermaat $\mathrm{H}$. Intact implicit learning in schizophrenia. Am J Psychiatry 2001;158:944-948.

85. Siegert RJ, Weatherall M, Bell EM. Is implicit sequence learning impaired in schizophrenia? A meta-analysis. Brain Cogn 2008;67:351-359.

86. Mulholland CC, O'Donoghue D, Meenagh C, Rushe TM. Errorless learning and memory performance in schizophrenia. Psychiatry Res 2008;159:180-188.

87. Kern RS, Liberman RP, Becker DR, Drake RE, Sugar CA, Green MF. Errorless learning for training individuals with schizophrenia at a community mental health setting providing work experience. Schizophr Bull 2009;35:807-815.

88. McGaugh JL. The amygdala modulates the consolidation of memories of emotionally arousing experiences. Annu Rev Neurosci 2004;27:1-28.

89. Phelps EA, Sharot T. How (and why) emotion enhances the subjective sense of recollection. Curr Dir Psychol Sci 2008; 17:147-152.
90. Draper ML, Stutes DS, Maples NJ, Velligan DI. Cognitive adaptation training for outpatients with schizophrenia. $J$ Clin Psychol 2009;65:842-853.

91. Wagner B. The training of attending and abstracting responses in chronic schizophrenics. J Exper Res Personal 1968;3:77-88.

92. Spaulding WD, Storms L, Goodrich V, Sullivan M. Applications of experimental psychopathology in psychiatric rehabilitation. Schizophr Bull 1986;12:560-577.

93. Choi J, Fiszdon JM, Medalia A. Expectancy-value theory in persistence of learning effects in schizophrenia: role of task value and perceived competency. Schizophr Bull 2010; 36:957-965.

94. Eack SM, Greenwald DP, Hogarty SS, Cooley SJ, DiBarry $\mathrm{AL}$, Montrose DM, et al. Cognitive enhancement therapy for early-course schizophrenia: effects of a two-year randomized controlled trial. Psychiatr Serv 2009;60:1468-1476.

95. Hogarty GE, Flesher S, Ulrich R, Carter M, Greenwald D, Pogue-Geile M, et al. Cognitive enhancement therapy for schizophrenia: effects of a 2-year randomized trial on cognition and behavior. Arch Gen Psychiatry 2004;61:866876.

96. Hogarty GE, Greenwald DP, Eack SM. Durability and mechanism of effects of cognitive enhancement therapy. Psychiatr Serv 2006;57:1751-1757.

97. Eack SM, Greenwald DP, Hogarty SS, Keshavan MS. One-year durability of the effects of cognitive enhancement therapy on functional outcome in early schizophrenia. Schizophr Res 2010;120:210-216.

98. Eack SM, Hogarty GE, Cho RY, Prasad KM, Greenwald DP, Hogarty SS, et al. Neuroprotective effects of cognitive enhancement therapy against gray matter loss in early schizophrenia: results from a 2-year randomized controlled trial. Arch Gen Psychiatry 2010;67:674-682.

99. Keshavan MS, Eack SM, Wojtalik JA, Prasad KM, Francis AN, Bhojraj TS, et al. A broad cortical reserve accelerates response to cognitive enhancement therapy in early course schizophrenia. Schizophr Res 2011;130:123-129.

100. Nuechterlein KH, Green MF, Kern RS, Baade LE, Barch $\mathrm{DM}$, Cohen JD, et al. The MATRICS Consensus Cognitive Battery, part 1: test selection, reliability, and validity. Am J Psychiatry 2008;165:203-213.

101. Gray JA, Roth BL. Molecular targets for treating cognitive dysfunction in schizophrenia. Schizophr Bull 2007;33:11001119 .

102. Goff DC, Hill M, Barch D. The treatment of cognitive impairment in schizophrenia. Pharmacol Biochem Behav 2011;99:245-253.

103. Haydar SN, Dunlop J. Neuronal nicotinic acetylcholine receptors - targets for the development of drugs to treat cognitive impairment associated with schizophrenia and Alzheimer's disease. Curr Top Med Chem 2010;10:144152.

104. Olincy A, Harris JG, Johnson LL, Pender V, Kongs S, Allensworth D, et al. Proof-of-concept trial of an alpha7 nicotinic agonist in schizophrenia. Arch Gen Psychiatry 2006;63:630-638.

105. Kantrowitz JT, Malhotra AK, Cornblatt B, Silipo G, Balla A, Suckow RF, et al. High dose D-serine in the treatment of schizophrenia. Schizophr Res 2010;121:125-130.

106. Buchanan RW, Keefe RS, Lieberman JA, Barch DM, Csernansky JG, Goff DC, et al. A randomized clinical trial of MK-0777 for the treatment of cognitive impairments in people with schizophrenia. Biol Psychiatry 2011;69:442449. 
107. Minzenberg MJ, Carter CS. Modafinil: a review of neurochemical actions and effects on cognition. Neuropsychopharmacology 2008;33:1477-1502.

108. Barch DM, Carter CS. Amphetamine improves cognitive function in medicated individuals with schizophrenia and in healthy volunteers. Schizophr Res 2005;77:43-58.

109. Daskalakis ZJ, Christensen BK, Fitzgerald PB, Chen R. Transcranial magnetic stimulation: a new investigational and treatment tool in psychiatry. $J$ Neuropsychiatry Clin Neurosci 2002;14:406-415.

110. Minzenberg MJ, Carter CS. Developing treatments for impaired cognition in schizophrenia. Trends Cogn Sci 2012;16:35-42.

111. Levkovitz Y, Rabany L, Harel EV, Zangen A. Deep transcranial magnetic stimulation add-on for treatment of negative symptoms and cognitive deficits of schizophrenia: a feasibility study. Int J Neuropsychopharmacol 2011;14: 991-996.

112. Vercammen A, Rushby JA, Loo C, Short B, Weickert CS, Weickert TW. Transcranial direct current stimulation influences probabilistic association learning in schizophrenia. Schizophr Res 2011;131:198-205.

113. Mulquiney PG, Hoy KE, Daskalakis ZJ, Fitzgerald PB. Improving working memory: exploring the effect of trans- cranial random noise stimulation and transcranial direct current stimulation on the dorsolateral prefrontal cortex. Clin Neurophysiol 2011;122:2384-2389.

114. Raffard S, Gely-Nargeot MC, Capdevielle D, Bayard S, Boulenger JP. Learning potential and cognitive remediation in schizophrenia. Encephale 2009;35:353-360.

115. Medalia A, Richardson R. What predicts a good response to cognitive remediation interventions? Schizophr Bull 2005;31:942-953.

116. Kurtz MM, Seltzer JC, Fujimoto M, Shagan DS, Wexler BE. Predictors of change in life skills in schizophrenia after cognitive remediation. Schizophr Res 2009;107:267274.

117. Bosia M, Bechi M, Marino E, Anselmetti S, Poletti S, Cocchi $\mathrm{F}$, et al. Influence of catechol-O-methyltransferase Val158Met polymorphism on neuropsychological and functional outcomes of classical rehabilitation and cognitive remediation in schizophrenia. Neurosci Lett 2007;417:271274.

118. Greenwood K, Hung CF, Tropeano M, McGuffin P, Wykes T. No association between the Catechol-O-Methyltransferase (COMT) val158met polymorphism and cognitive improvement following cognitive remediation therapy (CRT) in schizophrenia. Neurosci Lett 2011;496:65-69. 